\title{
Intraoral Lipoma of Palatal Mucosa
}

\author{
${ }^{1}$ Priyanka Tidke Munde, ${ }^{2}$ Prashant B Munde, ${ }^{3}$ Pradnya Jadhav
}

\begin{abstract}
Lipomas are most common, benign, soft tissue tumors in the body; however, they are rarely seen in the oral cavity. Intraoral lipomas are seen as benign, well-encapsulated swelling without pain with added yellowish tinge. We are presenting a case of an intraoral lipoma where the 22-year-old female presented a single well-encapsulated swelling in the posterior aspect of the palate on left side. The purpose of this report is to emphasize the need for dentists to be aware of frequency of occurrence of intraoral lipoma.
\end{abstract}

Keywords: Adipocytes, Intraoral, Lipoma, Palatal mucosa.

How to cite this article: Munde PT, Munde PB, Jadhav P. Intraoral Lipoma of Palatal Mucosa. J Contemp Dent 2016;6(2):142-144.

\section{Source of support: Nil}

Conflict of interest: None

\section{INTRODUCTION}

Lipomas are the commonest benign mesenchymal neoplasms of human body composed of mature adipocytes, usually surrounded by a fibrous capsule. Lipoma which is also called as fatty tumor is the commonest of benign tumors derived from the mesenchymal adipocytes and its prevalence is 15 to $20 \%$ in the head-neck region. Intraorally their occurrence is rare. ${ }^{1}$ Clinically, it is presented as asymptomatic, slowly progressing, soft and smooth-surface submucosal swelling that is most commonly located superficially and sometimes can be present deeply. In case of the superficial lipoma due to the thin mucosal covering, the added yellowish color tinge is seen most commonly and it helps to differentiate the lipoma from other soft tissue swellings. It can be presented as sessile or pedunculated mass, located frequently on buccal mucosa, tongue, floor of mouth, and sometimes lips. Its differentiation from the other soft tissue neoplasms is necessary to arrive at the correct diagnosis and

\footnotetext{
1,2 Senior Lecturer, ${ }^{3} \mathrm{Head} \&$ Professor

${ }^{1,3}$ Department of Oral Medicine and Radiology, MGM Dental College and Hospital, Navi Mumbai, Maharashtra, India

${ }^{2}$ Department of Oral Pathology and Microbiology, Aditya Dental College, Beed, Maharashtra, India

Corresponding Author: Priyanka Tidke Munde, Senior Lecturer Department of Oral Medicine and Radiology, MGM Dental College and Hospital, Navi Mumbai, Maharashtra, India, Phone: +919922225255, e-mail: tidke_priyanka@yahoo.com
}

to execute proper treatment plan. ${ }^{2}$ Here is a report of this uncommon clinical entity involving left palatal mucosa in a female patient along with clinical and histopathological features with no recurrence on follow-up.

\section{CASE REPORT}

A 22-year-old female patient presented with the chief complaint of growth in left back palatal mucosa since 1 month. The growth was initially small in size; gradually increased to a present size of $2 \times 1.5 \mathrm{~cm}$. Medical history was negative. General and systemic examination was normal without any associated disorder, and lymph nodes were normal on palpation. No significant findings were observed on extraoral examination. Intraoral examination showed a solitary pedunculated soft tissue growth in left posterior region of palatal mucosa since 1 month (Fig. 1). Occasionally, the patient complained of discomfort while eating. It was $2 \times 1.5 \mathrm{~cm}$ in size, oval in shape, and smooth surfaced. The overlying skin was of same color as that of adjacent mucosa with yellowish tinge and was not associated with any secondary changes. No history of trauma, pus, or blood discharge associated with growth. On palpation, the growth was mobile, nontender, and soft in consistency with well-defined margins. Based on history and clinical findings, a provisional diagnosis of intraoral lipoma was made. Routine hematological investigations were done and all were found to be in normal limit. Surgical excision of growth was performed. Excisional biopsy specimen revealed a single soft tissue specimen, whitish yellow in color, $1.5 \times 1 \mathrm{~cm}$ in size, oval

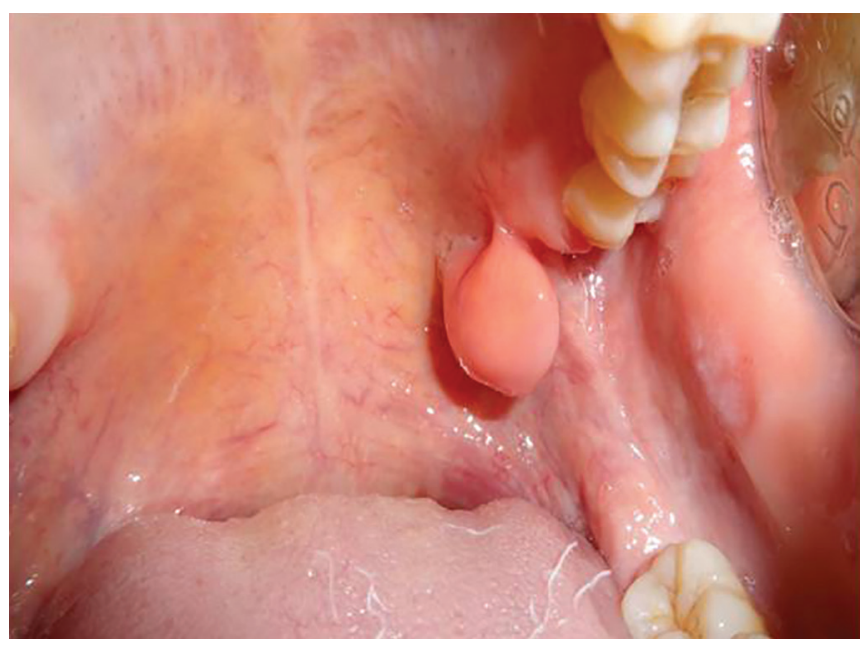

Fig. 1: Intraoral growth on left posterior palatal mucosa 


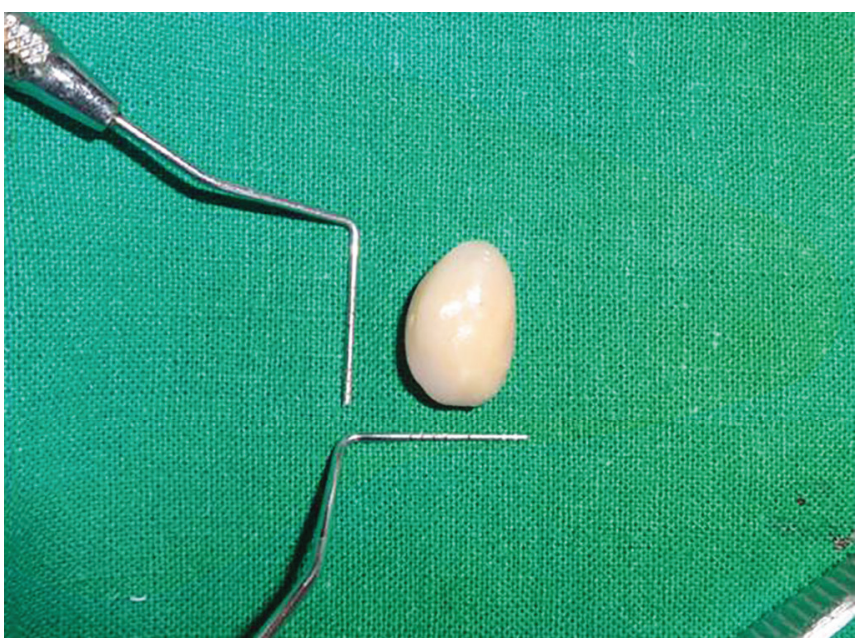

Fig. 2: Gross specimen

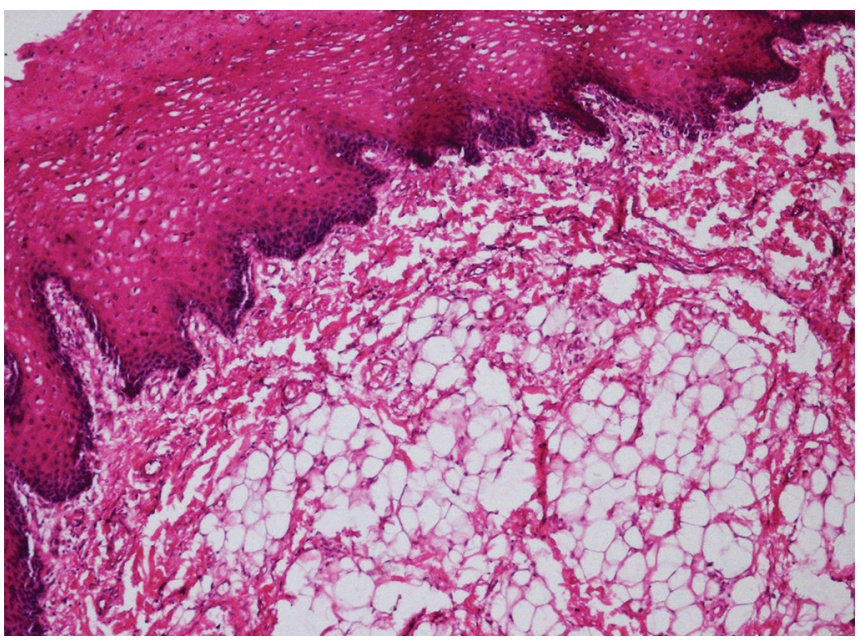

Fig. 4: Photomicrograph showing fibrocellular connective tissue stroma with adipocytes and hyalinization of collagen fiber bundles (H\&E stain, 100x)

in shape, soft in consistency with smooth surface texture (Fig. 2). Hematoxylin and eosin (H\&E)-stained sections of the excisional biopsy specimen showed thin atrophic parakeratinized stratified squamous epithelium with flattening of rete pegs and underlying connective tissue stroma (Fig. 3). The epithelium showed no features of dysplasia. The underlying connective tissue stroma was fibrocellular with adipocytes, and hyalinization of collagen fiber bundles, moderate number of fibroblasts were seen along with mild to moderate chronic inflammatory cell infiltrate chiefly of lymphocytes (Fig. 4). Histopathological examination showed mature adipocytes, with clear cytoplasm and eccentric nuclei (Fig. 5). These features were consistent with a classical diagnosis of a lipoma. Hence, the final diagnosis of intraoral lipoma of left palatal mucosa was made based on the clinical and histopathological findings. Postoperative follow-up was excellent without recurrence.

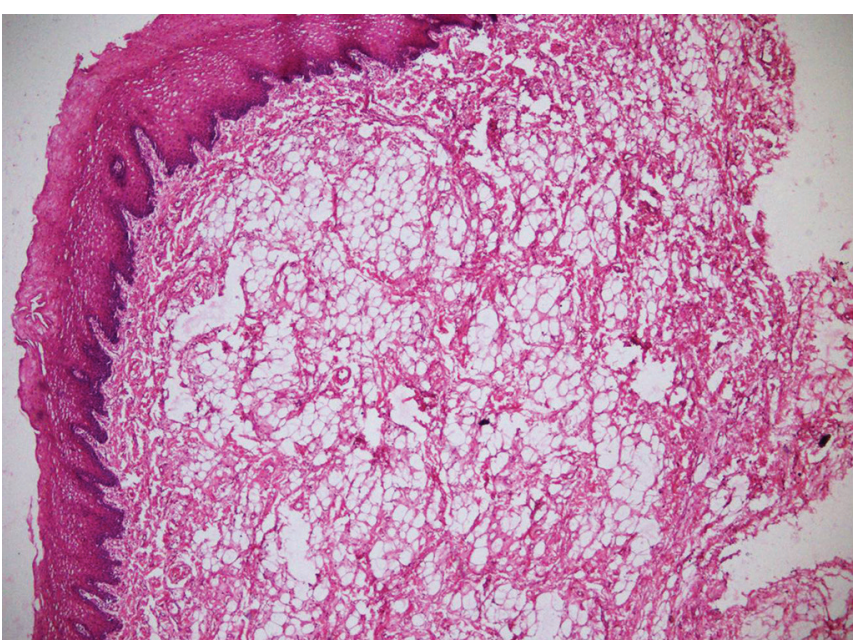

Fig. 3: Scanner view showing parakeratinized stratified squamous epithelium with flattening of rete pegs and underlying connective tissue stroma (H\&E stain, 40x)

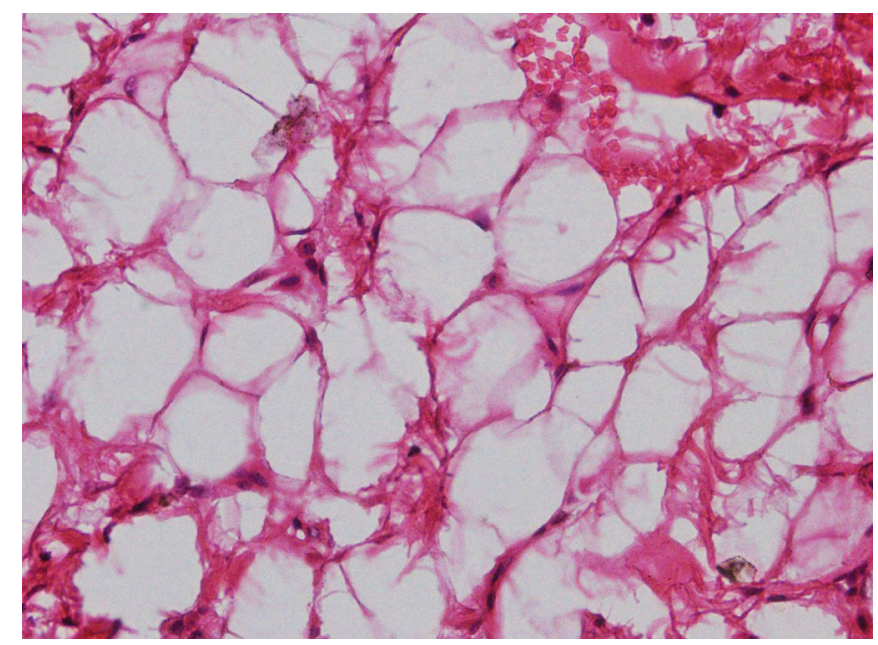

Fig. 5: Higher-power view showing empty adipocytes in connective tissue stroma (H\&E stain, 400x)

\section{DISCUSSION}

The lipoma is rarely seen intraorally with a prevalence rate of only $1 / 5,000 .{ }^{3}$ Lipomas are the most common soft tissue mesenchymal neoplasms, with 15 to $20 \%$ of cases involving the head and neck region and only 1 to $4 \%$ affecting the oral cavity. The etiology of lipoma is not exactly known but the obesity is considered as one of the most common factor. ${ }^{1}$ Although its etiology is unknown, possible causes may include trauma, infection, chronic irritation, and hormonal alterations. In few cases, rearrangement of chromosomes has been observed with respect to $12 q, 13 q, 6 p .{ }^{4}$ Clinically, it usually occurs in upper parts of the trunk, neck, and arms. Generally, no sex predilection occurs in patients older than 40 years. In oral cavity, it occurs on buccal mucosa and mucobuccal fold followed by tongue, floor of the mouth, lip, and gingiva. Lipomas are slowly enlarging, with a soft, smooth-surface 
mass of submucosal tissues. The asymptomatic nature, slow progression, smooth surface, soft consistency with added yellowish color tinge over the surface along with its slippery nature on palpation helps the clinicians to differentiate lipoma from other palatal soft tissue swellings. It grows as round or ovoid mass in oral cavity usually less than $3 \mathrm{~cm}$ at the time of diagnosis, but increases up to 5 and $6 \mathrm{~cm}$ over a period of years. Due to thinness of the overlying epithelium, yellow coloration of the fat can be seen. ${ }^{5}$ Morphologically, it can be seen in different types: Superficial: It appears as single or lobulated painless mass attached by sessile or pedunculated base. Yellow surface discoloration and well encapsulated. Surface epithelium is thin with superficial blood vessels visible.

Diffuse lipoma: Affecting deeper tissues producing slight surface elevation. Feels like fluid on palpation mistaken for cyst. Occurs in the areas of more fat deposit. Neurofibromatosis, Gardner syndrome, encephalocraniocutaneous lipomatosis, multiple familial lipomatosis, and proteus syndrome are some of the syndromes associated with multiple lipoma. ${ }^{4}$

The diagnosis of intraoral lipomas is usually clinical. Techniques like xeroradiography and echography are often used to delineate the anatomical extent of intraoral lesions but have limited capacity to precisely determine the extent of lesion. While considering advanced investigations, magnetic resonance imaging is the most sensitive investigation to study the soft tissue swellings and gives insight for the accurate diagnosis; but the histopathological investigation with staining is the gold standard for the diagnosis of fatty tumor. ${ }^{6}$ Histopathologically, lipomas like fat are composed of mature fat cells, but the cells vary slightly in size, shape, and are somewhat larger, measuring up to $200 \mathrm{~mm}$ in diameter. All lipomas are well vascularized, but under normal conditions, vascular network is compressed by the distended lipocytes and is not clearly visible. The fibrous connective tissue, which is often hyalinized and may or may not be associated with the capsule or the fibrous septa are called fibrolipomas. ${ }^{7}$ Instead of microscopic variations, the prognosis remains good. ${ }^{4}$ The treatment of oral lipomas, including all the histological variants, is a simple surgical excision. ${ }^{2}$
Liposuction is another option if the lipoma is soft and has a small connective tissue component. It results in less scarring; however, with large lipomas it may fail to remove entire tumor, which can lead to regrowth. ${ }^{8}$ There are new methods to remove the lipomas without scarring. Intra-lesional injections of steroids and phosphatidylcholine are the effective means for the management of lipomas. Lipomas are not life threatening and their transformation from benign to malignant is infrequent. ${ }^{9}$

\section{CONCLUSION}

Clinicians should have awareness that lipoma can occur in the oral cavity and be able to identify intraoral lipomas to provide appropriate treatment. Surgical excision is the ideal treatment with excellent outcome; however, complete resection should be done as this is the key factor to avoid recurrence.

\section{REFERENCES}

1. Studart-Soares EC, Costa FW, Sousa FB, Alves AP, Osterne RL. Oral lipomas in a Brazilian population: a 10-year study and analysis of 450 cases reported in the literature. Med Oral Patol Oral Cir Bucal 2010 Sep 1;15(5):e691-e696.

2. Fregman ER, Pires FR, Falzoni R, Lopes MA, Vargas PA. Lipomas of oral cavity. Int J Oral Maxillofac Surg 2003 Feb; 32(1):49-53.

3. Neville B, Damm DD, Allen CM, Bouquot J. Oral and maxillofacial pathology. Philadelphia (PA): Saunders; 2008. p. 523-524.

4. Rajendran R. Shafer's oral pathology. 5th ed. Amsterdam: Elsevier; 2006. p. 194-195.

5. Cawson RA, Binnie WH, Speight PM, Barrett AW. Lucas's pathology of tumors of the oral tissues. 4th ed. New York (NY): Churchill Livingstone; 1984. p. 176-179.

6. Epivatianos A, Markopoulos AK, Papanayotou P. Benign tumors of adipose tissue of the oral cavity: a clinicopathologic study of 13 cases. J Oral Maxillofac Surg 2000;58(10):1113-1117.

7. Weiss SW, Goldblum JR. Enzinger and Weiss's soft tissue tumors. 5th ed. Philadelphia (PA): Mosby; 2007. p. 571-639.

8. Al-basti HA, El-Khatib HA. The use of suction-assisted surgical extraction of moderate and large lipomas: long-term follow-up. Aesthetic Plast Surg 2002 Mar-Apr; 26(2):114-117.

9. Dalal KM, Antonescu CR, Singer S. Diagnosis and management of lipomatous tumors. J Surg Oncol 2008 Mar; 97(4): 298-313. 